\title{
Dynamic Analysis of Single Pile in Liquefied Soils Considered as Newtonian Fluid
}

\author{
Jinjing Sun ${ }^{1}$, Xinlei Zhang2* ${ }^{*}$ Zhihua Wang², Hongmei Gao², Lian Xu1 \\ ${ }^{1}$ The 3rd Geological Brigade of Jiangsu Geology \& Mineral Exploration Bureau, Nanjing, China \\ ${ }^{2}$ Urban Underground Space Research Center, Nanjing Tech University, Nanjing, China \\ Email: jinj_sun@yeah.net, ‘zxl201409@163.com, wzhnjut@163.com, hongmei54@163.com, xlnjtu@yeah.net
}

How to cite this paper: Sun, J.J., Zhang, X.L., Wang, Z.H., Gao, H.M. and Xu, L. (2021) Dynamic Analysis of Single Pile in Liquefied Soils Considered as Newtonian Fluid. Open Journal of Geology, 11, 19-37. https://doi.org/10.4236/ojg.2021.112002

Received: January 11, 2021

Accepted: February 1, 2021

Published: February 4, 2021

Copyright $\odot 2021$ by author(s) and Scientific Research Publishing Inc. This work is licensed under the Creative Commons Attribution-NonCommercial International License (CC BY-NC 4.0). http://creativecommons.org/licenses/by-nc/4.0/

\begin{abstract}
Case histories have shown that the liquefaction-induced soil lateral spreading is one of the main causes of damage to pile foundations subjected to seismic loading. Post-liquefaction soil behaves similarly to a viscous fluid. This study investigated the effect of soil lateral spreading on a single pile based on fluid mechanics in which the liquefied soils were treated as Newtonian fluids. A numerical simulation on a single pile embedded in a fully saturated sandy foundation was conducted and compared with shake table tests. The lateral flow effect and the effect of shear strain rate were discussed. After liquefaction, the acceleration of the foundation shows that there are no obvious spikes and finally reaches a stable state. The presented method can predict the pile response better than $\mathrm{p}-\mathrm{y}$ curve method. A parametric study was performed to explore the effect of several influence factors on pile behaviors. The results show that the pile head displacement decreases and the maximum bending moment at pile bottom increases with the increase of bending stiffness. With the same pile bending stiffness, the displacement and bending moment of pile increase with the increase of soil viscosity and acceleration amplitude.
\end{abstract}

\section{Keywords}

Pile, Liquefaction-Induced Lateral Spreading, Newtonian Fluid, CFD Method

\section{Introduction}

Pile foundations have been widely used to support bridges, ports, and harbor facilities that are located on liquefiable soils near a waterfront structure. In recent years, liquefaction resulting from seismic events has become a major concern due to its impact on structures, buildings, and other infrastructure during and after an earthquake. Almost all major earthquakes are accompanied by soil li- 
quefaction, as evidenced by the 1976 Tangshan earthquake in China [1], the 1989 Loma Prieta earthquake in the USA [2], the 1995 Hyogo-ken-Nambu earthquake in Japan [3], and the 2008 Wenchuan earthquake in China [4]. Liquefaction-induced ground failure has become one of the leading causes of infrastructure damage during an earthquake. Under seismic loading, the rapid increase in pore water pressure quickly decreases the shear strength of the unconsolidated sediment, possibly triggering large shear deformation. As flow failure of the ground during an earthquake may be caused by either the dynamic force due to the seismic acceleration or the static gravity force due to the topography of the ground [5]. Flow deformation of liquefied soil may continue under a gravitational load after the earthquake. The ground surface is prone to large-scale flow deformation regardless of whether it is flat or gently inclined. Uzuoak et al. [6] [7] suggested the shear strain of liquefied soil may exceed $100 \%$ and could develop into a regional seismic liquefaction event that could cause extensive damage. During the Tajik earthquake in 1989, the sliding mass traveled a distance of $2 \mathrm{~km}$ due to the liquefaction of the saturated soil, even though the ground surface was nearly flat [8].

To date, shake table experiments [9] [10] [11] centrifuge tests [12] [13], and field tests [14] have been extensively performed to investigate the pile behavior and elucidate the mechanical mechanism. Special attention has been paid to the problems of lateral flowing pressure on piles [15] [16] [17] liquefaction-induced drag forces on piles [18] [19], super-structure inertial effects [20], p-y spring behavior [14] [21], and the effects of upper non-liquefiable crust on the single pile and pile group response [22] [23]. These investigations highlighted an increased understanding of the effect of lateral spreading on pile foundations and associated mechanisms. The response of pile foundations to liquefaction-induced lateral spreading continues to be a complex problem. Therefore, the performance of pile under lateral spreading has been a research hotspot. It is found that the main reason for the pile damage in the earthquake is attributed to the excessive lateral movement of liquefied soils.

Liquefaction hazards are associated with substantial economic and personnel life losses. The large-scale deformation induced by liquefied soil is more serious and harmful to the subsurface structure than soil liquefaction itself. Previous studies of soil liquefaction have mainly focused on influencing factors, initial conditions, and liquefaction predictions. Recently, more attention has turned to the importance of the large-scale flow deformation associated with liquefaction. These studies were generally based on conventional solid mechanics and assumed a relatively limited maximum shear strain [24] [25]. However, the shear strain of the liquefied soil may exceed $100 \%$ in the large-scale flow condition which means the soil can change from solid-state to fluid-state.

In the past few years, a series of laboratory tests conducted by different researchers have shown that liquefied soil behaves similarly to a viscous fluid [26] [27] [28]. Due to the phase transition, it is difficult to apply solid mechanics based on small or finite deformation theory to describe the deformation proper- 
ties of the liquefied soil. Thus, a new analytical method is required. Computational fluid dynamics (CFD) is a computer-based method that makes use of a discretization of the algebraic equations governing flow and subsequent mathematical manipulation and solution. With the development of computer technology, numerical simulation methods have been rapidly developed, expediting the use of such applications as the CFD method to the study of liquefaction-induced flowing deformation. In recent years, a few preliminary attempts have been made to promote the application of the CFD method to the flowing deformation problems of liquefied soil [6] [28] [29]. However, the research is very limited compared with that using solid mechanics and hence there is no generally accepted theory concerning its use in describing non-linear deformation characteristics. Besides, there are few studies on large-scale flowing deformation caused by liquefaction.

In this paper, the liquefied sand was regarded as an incompressible Newtonian fluid. The pile-soil interaction was simulated and analyzed based on fluid-structure coupling theory, and the results were compared with the shake table model tests to verify the correctness of this method. Besides, the p-y curves method was adopted to compare with the numerical simulation results of pile response and discuss the lateral flow effect and the effect of the shear strain rates. Next, a parametric study was performed using the proposed method. Finally, the results were utilized to draw insights and conclusions, and future works were proposed to study the pile-soil interaction in laterally spreading ground.

\section{Numerical Modeling}

\subsection{Governing Equation}

In this study, liquefied sand is regarded as an incompressible fluid, and the numerical modeling involves the solution of the Navier-Stokes equations, which is based on the assumption of the conservation of mass and momentum. The conservation of mass is described by the following equation:

$$
\frac{\partial \rho}{\partial t}+\nabla(\rho \mathbf{u})=0
$$

and the conservation of momentum is described as:

$$
\frac{\partial \rho \boldsymbol{u}}{\partial t}+\nabla(\rho \mathbf{u u})=\rho \boldsymbol{f}_{v}+\nabla \boldsymbol{T}
$$

The fluid is assumed to follow the generalized Newton's Law; the constitutive model can be described as follows:

$$
\boldsymbol{T}=-p \boldsymbol{I}+2 \eta\left(\boldsymbol{S}-\frac{1}{3} \nabla \boldsymbol{u}\right)
$$

Applying the constitutive model Equation (3) to Equation (2) results in the Navier-Stokes equation:

$$
\frac{\partial \rho \boldsymbol{u}}{\partial t}+\nabla(\rho \boldsymbol{u u})=\rho \boldsymbol{f}_{\boldsymbol{v}}-\nabla \boldsymbol{p}+\frac{4}{3} \eta \Delta \boldsymbol{u}
$$

In Equation (1) to Equation (4), $\rho$ is the fluid density, $\boldsymbol{S}$ is the strain rate 
tensor, $\boldsymbol{f}_{v}$ is the volume force, $\boldsymbol{u}$ is the velocity tensor, $\eta$ is the viscosity, $\boldsymbol{T}$ is the stress tensor, and $\boldsymbol{p}$ is the static pressure.

To solve the Navier-Stokes equations, the PISO algorithm [30] [31] is used. This is a pressure-velocity calculation procedure based on a finite volume discretization on a staggered grid of the governing equations. The purpose of a staggered grid is to evaluate scalar variables, such as pressure and density, at ordinary nodal points, while velocities are defined at the cell faces between the nodes. The arrangement for a two-dimensional flow calculation is shown in Figure 1. The PISO algorithm provides a higher degree of accuracy for pressure and velocity corrections than the SIMPLE algorithm [32], which was used by Uzuoka et al. [6] in the analysis of liquefaction-induced lateral spreading.

\subsection{Elements, Materials and Boundary Conditions}

Based on the above principle, the pile-soil interaction problem was analyzed by the iterative coupling method based on ADINA finite element software, and the stress distribution and displacement of pile foundation were calculated and analyzed. To investigate the dynamic response of pile foundations in the liquefied ground, results from the shake table test conducted by Le Su [33] (e.g. Figure 2) were used to demonstrate the accuracy of the numerical modeling. The input ground motion applied in the shake table test is presented in Figure 3.

In the FE model, the saturated soil was simulated as an incompressible fluid. The steel pipe pile was modeled as solid elements with the properties of an elastic section. A fluid-solid coupling surface was set up between the pile and liquefied soil. Due to different modules, the discretization of the model is illustrated in Figure 4. Each node of the pile element is comprised of three displacement degrees of freedom and three for rotations. The grid of soil elements around the pile was finer than those far from the pile. In structure modules, the bottom boundary was assumed fixed in the $\mathrm{Y}$ and $\mathrm{Z}$ directions, and free in $\mathrm{X}$ direction. In total, a 3D finite element mesh comprising 288 solid elements and 208 shell elements was used. The 32 spring elements were installed to the bottom of the pile, and the rotational stiffness of each spring element was $3.75 \mathrm{kN} \cdot \mathrm{m} / \mathrm{rad}$. While in fluid modules, the front and rear boundary was assumed fixed on $\mathrm{Y}$-axis, and the velocity was set as zero on $\mathrm{X}$-axis. In total, a finite element mesh comprising 3120 fluid elements was used in the analysis, as shown in Figure 4.

The pile is considered as a linear elastic material. The constitutive behavior of the soil is captured by the fluid material since it is assumed as a fluid. Material parameters are shown in Table 1.

Table 1. Parameters used for the simulation.

\begin{tabular}{cccc}
\hline Physical quantity & Pile & Liquefied Soil & Water \\
\hline Modulus of elasticity, $E(\mathrm{GPa})$ & 190 & $/$ & $/$ \\
Density, $\rho\left(\mathrm{kg} \cdot \mathrm{m}^{-3}\right)$ & 2500 & 1800 & 1000 \\
Possion's ratio, $v$ & 0.29 & $/$ & $/$ \\
Viscosity, $\eta(\mathrm{kPa} \cdot \mathrm{s})$ & $/$ & 20 & 0.001 \\
\hline
\end{tabular}




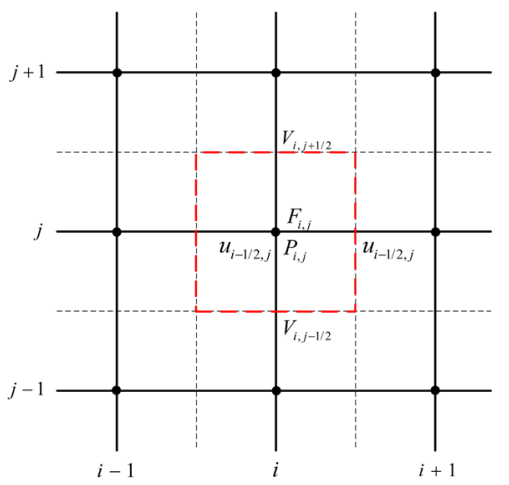

Figure 1. Locations of variables in staggered grid.

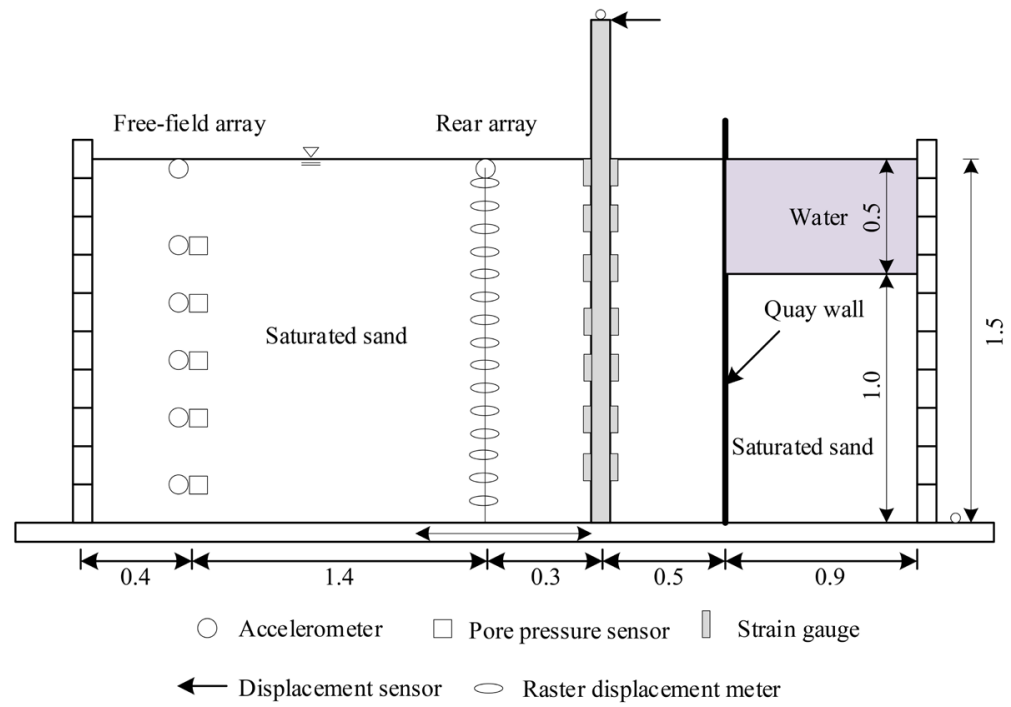

Figure 2. Layout of the model for shaking table test by Le Su [33].

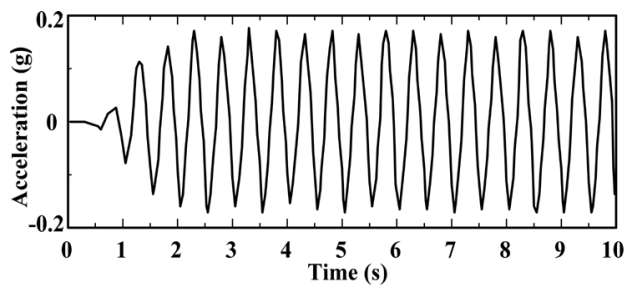

Figure 3. Acceleration time history of input motion.

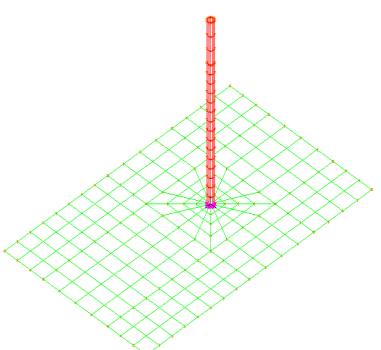

(a)

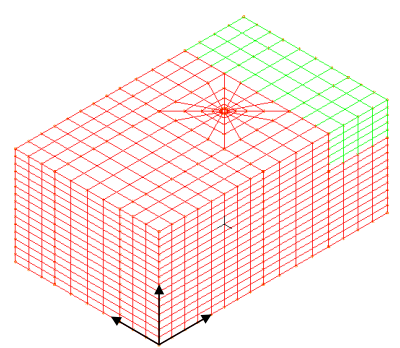

(b)

Figure 4. Calculation grid and monitoring of shake table test analysis (a) Structure finite element mesh; (b) Fluid finite element mesh. 


\subsection{Calculation Process}

The analysis was carried out in three steps: 1) the soil and pipe pile mesh were built. The pile and soil were assigned elastic properties and fluid, respectively, and the static gravity of the model was applied to establish the initial stress states in the soil. The values of stress in this stage were used as initial values for the next stage of loading; 2 ) the spring elements were incorporated into the model; 3) the dynamic analysis was performed by application of the input motion to the model base. The transient dynamic nonlinear analysis was performed with 1000 steps of $0.001 \mathrm{~s}$. The Newmark method was used to integrate the dynamic response with $\alpha=0.25$ and $\delta=0.5$ for convergence. Besides, the modified Newton-Raphson algorithm was used to solve system equations.

\section{Validation and Analysis}

The responses of the soil and the pile are presented in this section and compared with the recorded data of the shake table test. To demonstrate the accuracy of the numerical model, only the results of shake table test with rotational stiffness of $120 \mathrm{kN} \cdot \mathrm{m} / \mathrm{rad}$ were presented here.

\subsection{Displacement and Bending Moment of Pile}

As shown in Figure 5, the displacement time-history response of pile head can be divided into the following three stages: Stage 1 (0-2.3 section) before liquefaction, Stage 2 (2.3-6.8 section) during liquefaction-induced lateral spreading, and Stage 3 (6.8-10 section) without lateral spreading observed. So, the lateral soil displacements in Stage3 are not discussed here. The pile head displacements from the calculation are similar to those from experimental results, although the amplitude of fluctuation by calculation is greater than the experiment. Before the soil begins to liquefy (2.3s), due to the apparent viscosity difference between the soil and the water, there is a distinct upward stage. Thereafter, the amplitude of the pile head displacements essentially remained constant.

Figure 6 displays the displacement and bending moment of the pile at various depths. The simulation results by fluid mechanics are consistent with the experimental results. As expected in this cantilever beam configuration, the bending moments gradually increase along with the depth, and the maximum bending moment $\left(M_{\max }\right)$ occurs near the base. However, the displacement response of pile decreases gradually along with the depth of foundation, which is contrary to the bending moment response of pile. The lateral displacement of the pile reaches the maximum at the pile head. The simulated pile displacement is slightly less than that from the experiment, and the difference between them can be corrected by adjusting the soil viscosity parameters.

\subsection{Soil Acceleration}

The acceleration responses of soil in shake table tests could be divided into three main stages. In Stage 1, the amplitude of soil acceleration gradually increased. 


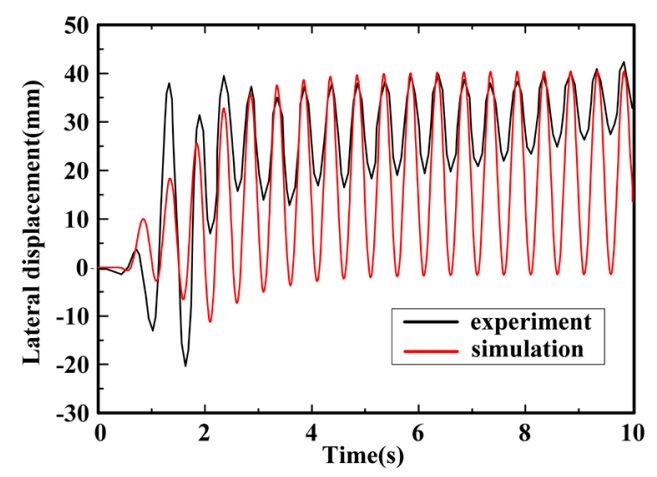

Figure 5. Lateral displacements of pile head.

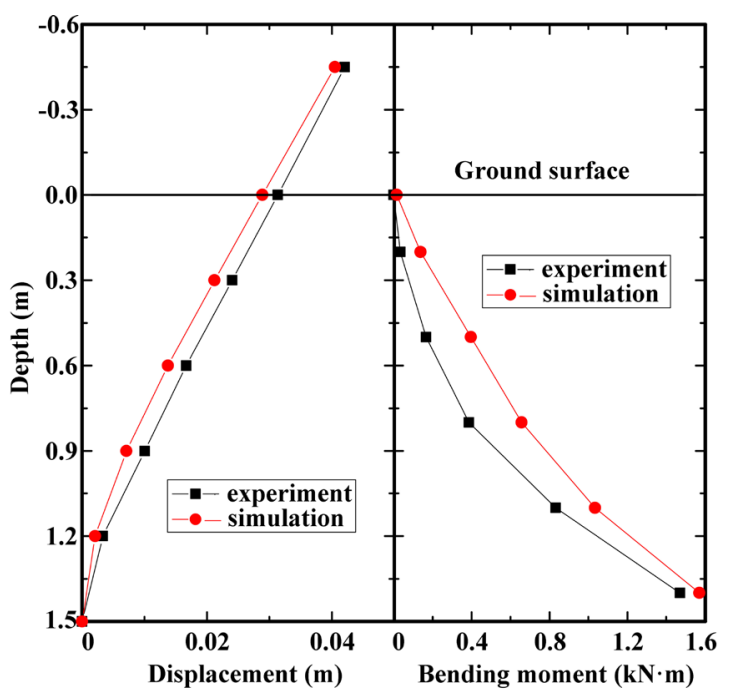

Figure 6. Displacement and bending moment of pile response.

The excess pore pressure, $u_{e}$ developed rapidly in soil foundation, and the soil reached the initial liquefaction state in this stage. In Stages 2 and 3, the acceleration attenuated significantly as the sand stratum liquefied and then remained constant at a low level, indicating that the liquefied sand had very low shear strength. But the numerical modeling does not well simulate the acceleration response of the soil layer along with the depth in Stage 1, since the fluid had a low shear strength at a high shear strain. It can compare with the experiment in Stage 3.

Figure 7 depicts the free-field accelerations from simulation compared with the experiment. From the experimental results, it can be found that the number of seismic cycles required for soil liquefaction differed in depth. For deep soil layers, it is difficult to liquefy, and more seismic cycles are needed. Besides, the acceleration response of the soil layer along the depth in Stage 1 is greater than that in Stage 3. Since the soil layer becomes liquefied, post-liquefaction soil behaves similarly to a viscous fluid. The fluid can bear the great shear strain and consume the energy of seismic waves, so the acceleration of the soil layer changes slightly. In addition, taking the soil acceleration at $1.1 \mathrm{~m}$ depth as an example, the calculated free field acceleration is consistent with the experimental 


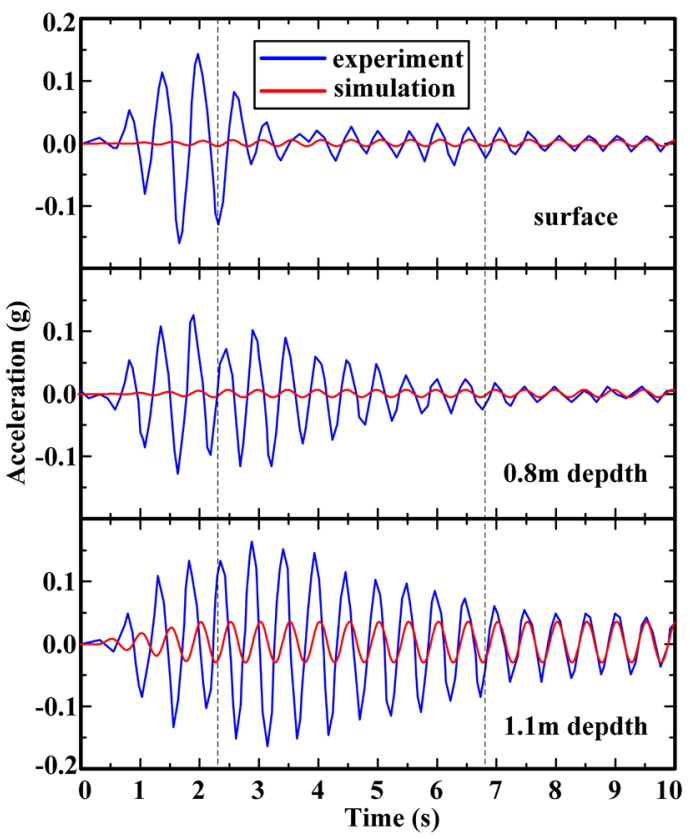

Figure 7. Comparison of simulated free field acceleration with experimental results.

result in Stage 3, but the frequency of simulated soil acceleration is lower than the frequency of base excitation in Stage 1 and Stage 2. Therefore, in the process of phase transformation, the frequency of soil acceleration changes, and the acceleration response of soil reaches a stable state after liquefaction. With the increase of excess pore pressure, the soil softens and the natural frequency decreases gradually, and the shear strain rate increases with the decrease of frequency.

\subsection{Lateral Soil Pressure}

Currently, two simple lateral soil pressure profiles (uniform and triangular) for a single pile subjected to lateral soil flow induced by liquefaction have been proposed. The first profile recommends a uniform soil pressure profile proposed by Dobry et al. [34]. Another profile, provided by JRA [35], recommends a triangular soil pressure profile. This soil pressure can be expressed as

$$
p=K \gamma z
$$

where $p$ is the lateral soil pressure, and $\gamma$ represents the total unit weight of overburden soil, $K$ is soil pressure coefficient, and $z$ is soil depth. JRA recommends a coefficient $K$ with a value of 0.3 .

Applying these approaches to the results of this study, the uniform soil pressure and coefficient $K$ can be estimated based on matching the measured bending moment. In this regard, the soil pressure can be integrated readily along the depth to obtain the bending moment and pile displacement [36]. Figure 8 shows the profiles of soil pressure, compared with the BNWF model which is described by Le Su [33]. A uniform soil pressure $p=4.8 \mathrm{kPa}$ and a coefficient $K=0.7$ were calibrated to approximate the trend of the observed bending moment, but with 
an underestimation of the soil pressure at the base. This calculated soil pressure shows a similar parabolic profile along with the depth, which is similar to the BNWF model. This further illustrates the inadequacy of employing a strictly linear soil pressure distribution.

\section{Comparison with p-y Curve}

\subsection{Beam on Nonlinear Winkler Foundation Model}

Figure 9 shows an idealized schematic of the adopted BNWF model for the analysis of a single pile subjected to lateral spreading. This model employs an elastic beam element to simulate the pile and a nonlinear $p-y$ spring element to represent the behavior of soil-pile interaction. The pile base connection finite stiffness is defined using a zero-length element with a rotational spring constant $K_{s}$, and more details can be found in Le Su [33].

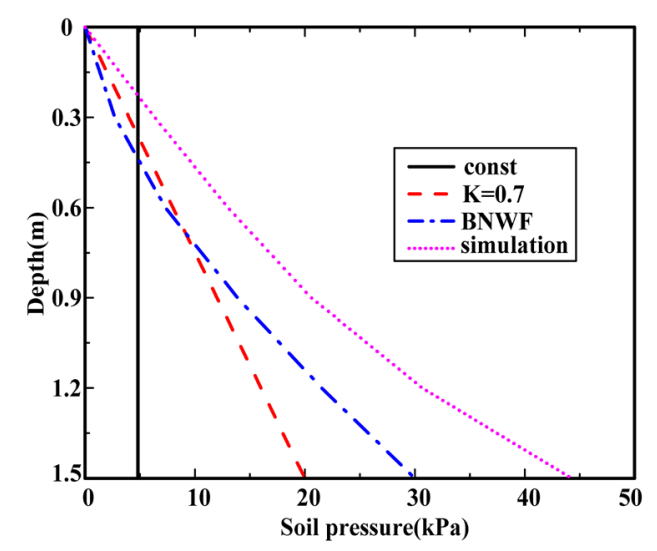

Figure 8. Comparison of soil pressure with various methods.

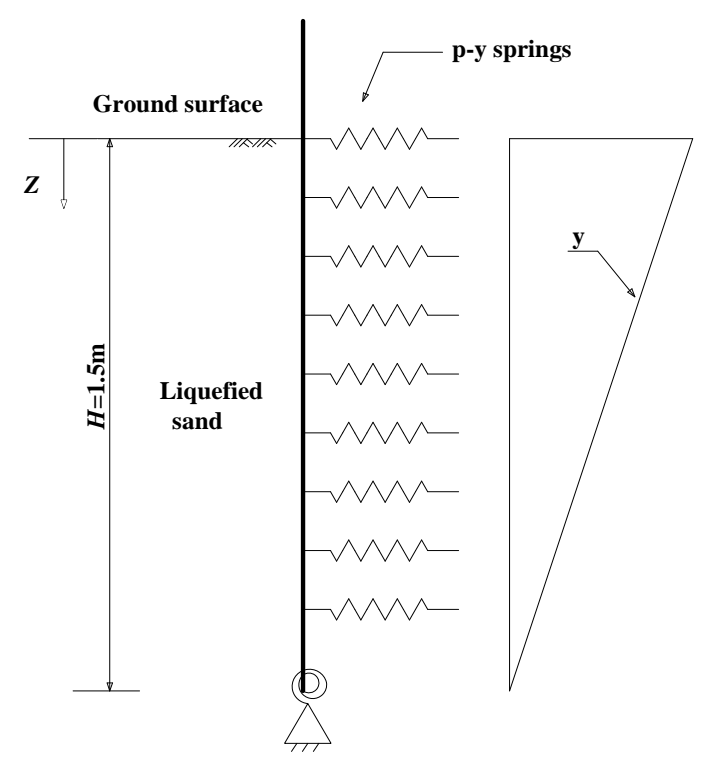

Figure 9. BNWF model of single pile under lateral spreading conditions. 
In the BNWF model, the behavior of the nonlinear p-y spring element is described by American Petroleum Institute [37]. In the p-y spring element, two critical parameters must be determined according to the configuration of the soil and pile. One parameter is the ultimate capacity of liquefied sand, $p_{u}^{\text {liq }}$, and the other is the initial modulus of the subgrade reaction, $k$. The ultimate capacity (force per length of the pile, $p_{u}$ ) of the non-liquefied sand is obtained by the following [38]:

$$
p_{u}=\left(C_{1} H+C_{2} D\right) \gamma H
$$

where $C_{1}, C_{2}$ are related to the internal friction angle, $\psi$ (see Table 2), $\gamma$ is the weight of soil, $H$ is the soil depth, and $D$ is the diameter of pile.

Here, the equation proposed by American Petroleum Institute [37] is employed as:

$$
p=A p_{u} \tanh \left(\frac{k h}{A p_{u}} y\right)
$$

where $A$ is the influence factor of dynamic load which is set as $0.9, h$ is the depth of soil, and $y$ is the displacement of pile.

Note that both $p_{u}$ and $k$ must be further modified to take the liquefaction effect into account. Therefore, Li et al. [39] conducted eight shake table experiments on a single pile in the liquefiable ground to get parameters $p_{u}$ and $k$. Parameters $p_{u}$ and $k$ were modified as follows:

$$
\begin{gathered}
p_{u}^{l i q}=\alpha p_{u} \\
k_{\text {liq }}=\beta k
\end{gathered}
$$

where $\alpha$ and $\beta$ are the liquefaction effect modification factors, derived from $D_{r}$ :

$$
\begin{gathered}
\alpha=(0.026 \mathrm{z} / l+0.055) \mathrm{e}^{0.016 D_{r}} \\
\beta=(3.195 \mathrm{z} / l+0.495) D_{r}^{-1.45}
\end{gathered}
$$

where $e$ is Euler's number, $z$ is pile depth below the ground surface, $I$ is pile length and $D_{r}$ is the relative density of soil.

Based on the modified ultimate capacity and initial modulus, the equation is modified as follows:

$$
p=A p_{u}^{l i q} \tanh \left(\frac{k_{l i q} h}{A p_{u}^{l i q}} y\right)
$$

Table 2. Parameters selected for BNWF models.

\begin{tabular}{ccc}
\hline$\psi$ & $C_{1}$ & $C_{2}$ \\
\hline 30 & 1.95 & 2.7 \\
32 & 2.1 & 2.9 \\
34 & 2.9 & 3.4 \\
36 & 3.2 & 3.6 \\
38 & 4.0 & 4.0 \\
$>40$ & 4.6 & 4.35
\end{tabular}


According to the experimental configuration and the aforementioned formulas, the soil spring parameters ( $p_{u}^{l i q}$ and $k_{\text {liq }}$ ) in the BNWF model can be calculated.

\subsection{Results and Discussion}

As shown in Figure 10, the calculated pile responses using p-y method are compared with the results obtained by the proposed method to verify the reliability of the simulation method. The simulation method established in this study to estimate the response of piles in the seismic load by treating the liquefied soil as the liquid is shown to provide good agreement with the $\mathrm{p}-\mathrm{y}$ method, although the simulated pile bending moments are slightly less than the values of calculation.

Moreover, the simulated pile head displacement is closer to the experimental one compared to that obtained from p-y method. It can be seen that the method of analyzing pile response under dynamic load is reasonable when the liquefied soil is regarded as fluid.

\subsection{Lateral Flow Effect}

At present, there are many methods for the pile-soil interaction, such as the p-y curves and $m$ method. These methods are based on solid mechanics theory, without considering the lateral flow effect of liquefied soil, thus underestimating the soil-pile interaction, especially for the lateral expansion of fully liquefied soil. The $m$ method cannot describe the force acting on the pile at the pile-soil interface, which ignores the effect of the soil movement during the earthquake. The p-y curve method describes the interaction of pile-soil interaction inaccurately, due to the development of pore pressure and the flow effect of liquefied soil. There is an obvious correlation between the flow effect and soil-pile interaction. The existing methods do not consider the influence of the flow effect and the excess pore pressure of the liquefied soil on the response of the pile foundation. Therefore, it is necessary to establish a new method, which can be used for the analysis of pile-soil interaction in the liquefied foundation.

The comparison of pile responses using the proposed simulation method and p-y method under different liquefaction soil flow velocities, $V$, is shown in Figure 11. The pile head displacement increases from $4 \mathrm{~cm}$ to $10 \mathrm{~cm}$ with the change in velocity from $0 \mathrm{~m} / \mathrm{s}$ to $0.15 \mathrm{~m} / \mathrm{s}$ because a larger velocity can mobilize a greater soil wedge behind the pile. Therefore, the bending moment and pile displacement of pile increase with the increase of velocity under the same bending stiffness.

It can be seen that the flow effect of liquefied soil cannot be neglected, and the effect is more obvious when the velocity is greater. Due to the flow effect of the liquefied soil, the force will increase, resulting in additional internal stress and deformation of the pile foundation, so the pile foundation seismic design needs to consider the flow effect of the liquefied stratum. For liquefied soils with lateral spread, the existing methods must be modified to avoid underestimating the pile-soil interaction. 


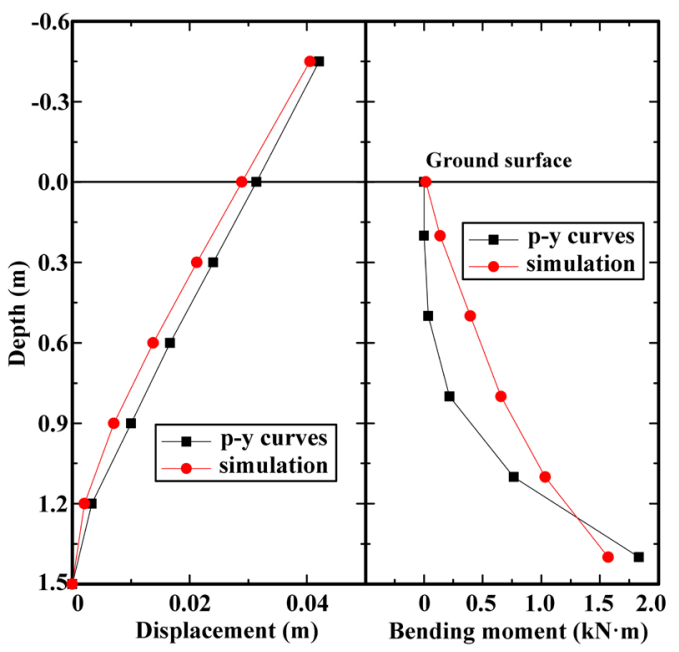

Figure 10. Comparison of pile response obtained by simulation and $\mathrm{p}-\mathrm{y}$ method.

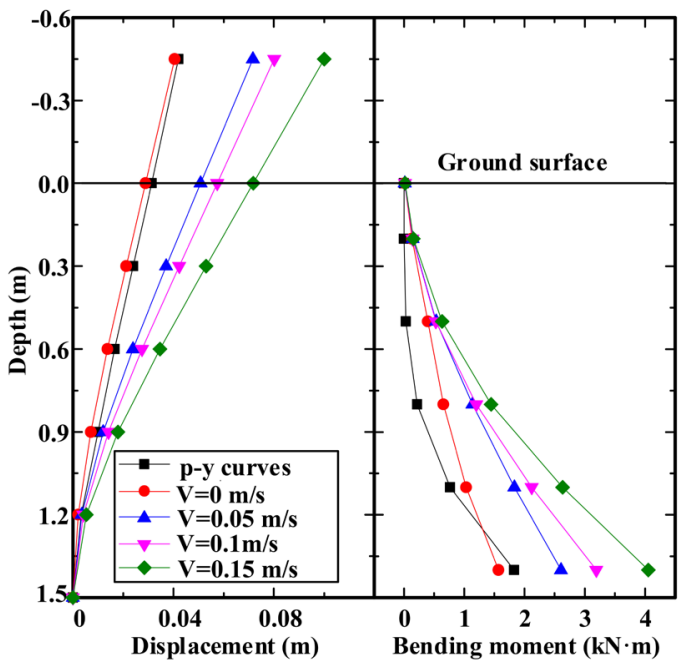

Figure 11. The lateral flow effect on pile response.

\subsection{Effect of Shear Strain Rates}

In the soil liquefaction process, with the increase of pore pressure, the viscosity of soil decreases, but the corresponding shear strain rate increases gradually, which leads to the increase of shear stress of pile. Loading frequency is not an important factor affecting soil dynamic strength, but it affects the accumulation of pore pressure [40]. Although the soil nonlinearity during the pore pressure development is considered by the $\mathrm{p}-\mathrm{y}$ curve method, the shear strain rate is not considered. Under cyclic loading, the greater the loading frequency, the greater the strain rate [41]. The results of pile-soil interaction may be closely related to the strain rate. Here, the effect of frequency on pile-soil interaction is discussed. Shear rates corresponding to different frequencies are shown in Figure 12. The frequency has a significant effect on shear strain rate, indicating that the shear strain rate of soil increases with the increase of loading frequency. 


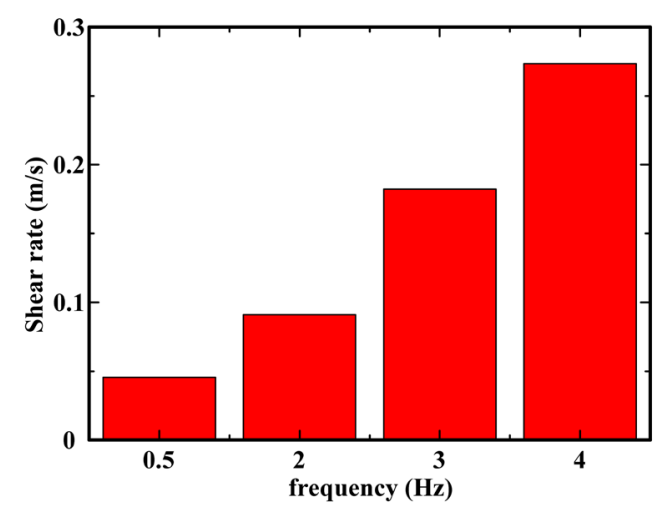

Figure 12. Shear rates corresponding to different frequencies.

Figure 13 shows the effect of frequency on pile response. The pile head displacement increases from $0.038 \mathrm{~m}$ to $0.048 \mathrm{~m}$, and the pile bending moment increases from $1.15 \mathrm{kN} \cdot \mathrm{m}$ to $1.83 \mathrm{kN} \cdot \mathrm{m}$ as the frequency varies from $0.5 \mathrm{~Hz}$ to 3 $\mathrm{Hz}$, respectively. From the numerical simulation results, it can be found that the difference in frequency leads to the difference in soil shear strain. The effect of shear strain rate should be considered in the analysis of pile-soil interaction during the liquefaction process.

\section{Parametric Study}

\subsection{Influence of the Pile Modulus}

The influence of pile modulus $E$ on the pile response is shown in Figure 14. Increasing the pile modulus can reduce the pile lateral displacement, but lead to the gradual increase in the bending moment of the pile.

\subsection{Influence of Soil Viscosity}

The influence of soil viscosity, $\eta$, on the pile response is shown in Figure 15. With the increase of soil viscosity $\eta$ from $10 \mathrm{kPa} \cdot \mathrm{s}$ to $50 \mathrm{kPa} \cdot \mathrm{s}$, the displacement of pile head increases from $3.8 \mathrm{~cm}$ to $6.9 \mathrm{~cm}$, and the maximum bending moment at pile bottom increases from $1.2 \mathrm{kN} \cdot \mathrm{m}$ to $3.6 \mathrm{kN} \cdot \mathrm{m}$, respectively. The greater the soil viscosity, the greater the lateral force acting on the pile, and the greater the bending moment and lateral displacement of the pile. Ramos et al [42] indicate that when $\eta$ is large, the pile displacement is mainly caused by the deformation of pile. However, for a smaller $\eta$, the pile displacement should be the sum of the displacement related to the deformation of the pile and the displacement related to the rotation of the pipe.

\subsection{Influence of the Acceleration Amplitude}

As shown in Figure 16, the pile head displacement increased from $1.1 \mathrm{~cm}$ to 6.8 $\mathrm{cm}$ with the change in acceleration amplitude from $0.05 \mathrm{~g}$ to $3 \mathrm{~g}$, respectively. For the same soil viscosity, the pile bending moment increased with the increment in acceleration amplitude. In this regard, the greater bending moment resulted in a larger pile displacement. It shows that the pile will have a large lateral 
displacement due to the lateral spreading of the liquefied soil, which will increase the overall displacement of the supporting structure.

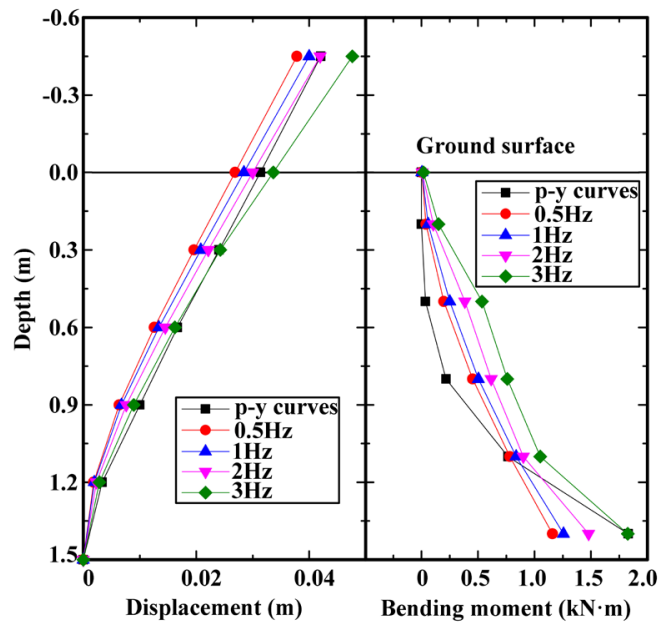

Figure 13. The effect of frequency on pile response.

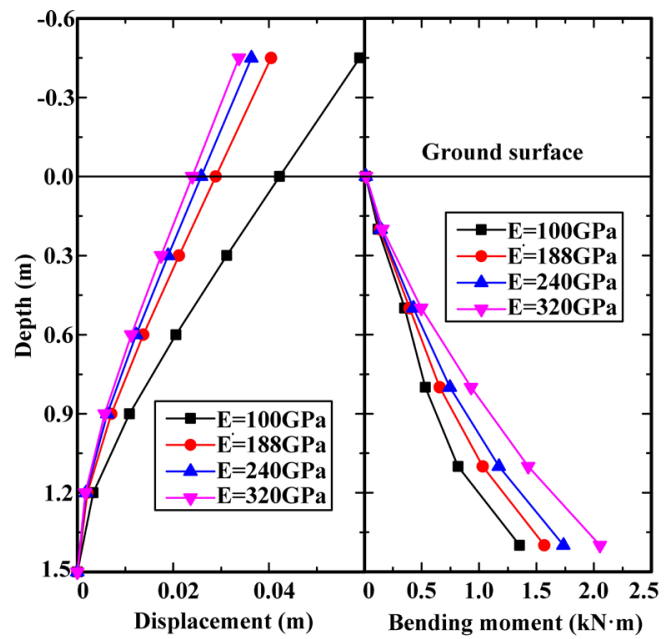

Figure 14. Influence of $E$ on pile response.

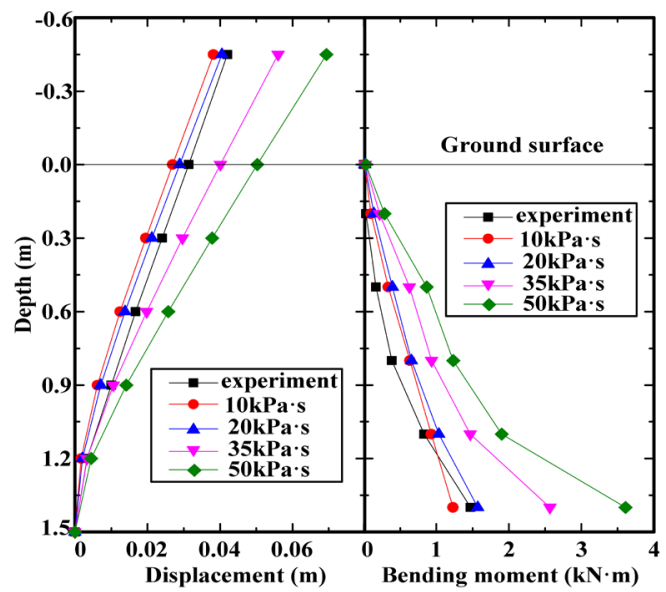

Figure 15. Influence of $\eta$ on pile response. 


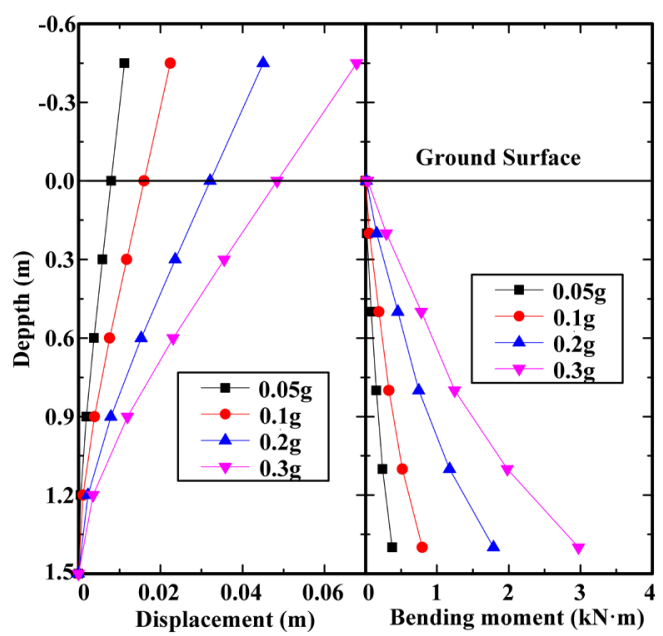

Figure 16. Influence of acceleration amplitude on pile response.

\section{Conclusions}

Based on the fluid mechanics, the pile-soil interaction simulation model under the condition of liquefaction-induced large lateral spreading was established by taking liquefied soil as a Newtonian fluid. The simulation results were compared with the shake table test and p-y method to study the behavior of piles subjected to the flow of liquefied soils. The influencing factors of pile-soil interaction in laterally spreading ground are analyzed. The following conclusions can be drawn:

1) The behavior of liquefied soil is similar to that of viscous fluid. The pile-soil interaction can be well simulated based on fluid mechanics theory which treated liquefied soil as fluid.

2) There are no obvious spikes of soil acceleration, which indicates that the liquefied soil can bear the large shear strain and consume seismic wave energy. In the process of liquefaction, the natural frequency of soil layer decreases slightly with the phase transformation, and finally reaches a stable state. It is unreasonable to assume that the distribution of soil pressure is strictly linear along the depth direction, which may underestimate the soil pressure at the pile bottom.

3) The p-y curves method for analyzing the behavior of the pile under lateral spreading was adopted to validate the numerical simulation response. Lateral flow effects exacerbate the pile response, both in pile head displacement and bending moment. A larger frequency leads to large shear strain rates in soil, and the pile will undergo a relatively large lateral displacement and bending moment due to larger shear strain rates. The effects of lateral flow and shear strain rates are not considered by p-y curves. Compared with p-y curves, the method proposed in this study is more reasonable.

4) The results show that the pile head displacement decreases with the increase of bending stiffness, but the maximum bending moment at pile bottom increases slightly. With the same pile bending stiffness, the displacement and bending moment of pile increase with the increase of soil viscosity and accelera- 
tion amplitude.

It should be noted that more shake table tests and numerical simulations with various scenarios should be conducted to investigate more influencing factors such as time-varying viscosity, overburden pressure, and earthquake parameters, which are also significant in the seismic design of pile foundations under lateral spreading.

\section{Acknowledgements}

This work was supported by the National Natural Science Foundation of China (grant number 51678300) and Middle-aged \& Young Science Leaders of Qinglan Project of Universities in Jiangsu Province, China. These financial supports are gratefully acknowledged. The contributions of anonymous reviewers and editors are also acknowledged.

\section{Conflicts of Interest}

The authors declare no conflicts of interest regarding the publication of this paper.

\section{References}

[1] Fu, S.C. and Tatsuoka, F. (1984) Soil Liquefaction during Haicheng and Tangshan Earthquake in China; a Review. Soils Foundations, 24, 11-29. https://doi.org/10.3208/sandf1972.24.4 11

[2] Bartlett, S.F. and Youd, T.L. (1995) Empirical Prediction of Liquefaction Induced Lateral Spread. Journal of Geotechnical Engineering, 121, 316-329. https://doi.org/10.1061/(ASCE)0733-9410(1995)121:4(316)

[3] Shibata, T., Oka, F. and Ozawa, Y. (1996) Characteristics of Ground Deformation Due to Liquefaction. Soils and Foundations, 36, 65-79. https://doi.org/10.3208/sandf.36.Special 65

[4] Huang, Y. and Jiang, X.M. (2010) Field-Observed Phenomena of Seismic Liquefaction and Subsidence during the 2008 Wenchuan Earthquake in China. Natural Hazards, 54, 839-850. https://doi.org/10.1007/s11069-010-9509-6

[5] Tamate, S. and Towhata, I. (1999) Numerical Simulation of Ground Flow Caused by Seismic Liquefaction. Soil Dynamics and Earthquake Engineering, 18, 473-485. https://doi.org/10.1016/S0267-7261(99)00022-6

[6] Uzuoka, R., Yashima, A., Kawakami, T. and Konrad, J.M. (1998) Fluid Dynamics Based Prediction of Liquefaction Induced Lateral Spreading. Computers and Geotechnics, 22, 243-282. https://doi.org/10.1016/S0266-352X(98)00006-8

[7] Huang, Y., Mao, W., Zheng, H. and Li, G.H. (2012) Computational Fluid Dynamics Modeling of Post-Liquefaction Soil Flow Using the Volume of Fluid Method. Bulletin of Engineering Geology and the Environment, 71, 359-366. https://doi.org/10.1007/s10064-011-0386-3

[8] Ishihara, K. (2009) Liquefaction-Induced Flow Slide in the Collapsible Loess Deposit in Tajik. Earthquake Geotechnical Case Histories for Performance-Based Design, ISSMGE TC4 2005-2009 Term Volume, 431-448. https://doi.org/10.1201/NOE0415804844.ch26

[9] Yuan, X.M., Li, Y.R. and Sun, R. (2008) Mechanism of Pile Foundation Response in 
Liquefiable Soils under Seismic Cyclic Ground Motion. China Civil Engineering Journal, 41, 103-110. (In Chinese)

[10] Tang, L. and Ling, X.Z. (2014) Response of a RC Pile Group in Liquefiable Soil: A Shake-Table Investigation. Soil Dynamics and Earthquake Engineering, 67, 301-315. https://doi.org/10.1016/j.soildyn.2014.10.015

[11] Motamed, R. and Towhata, I. (2009) Shaking Table Model Tests on Pile Groups behind Quay Walls Subjected to Lateral Spreading. Journal of Geotechnical and Geoenvironmental Engineering, 136, 477-489. https://doi.org/10.1061/(ASCE)GT.1943-5606.0000115

[12] Abdoun, T., Dobry, R., O’Rourke, T.D. and Goh, S.H. (2003) Pile Response to Lateral Spreads: Centrifuge Modeling. Journal of Geotechnical and Geoenvironmental Engineering, 129, 869-878.

https://doi.org/10.1061/(ASCE)1090-0241(2003)129:10(869)

[13] Imamura, S., Hagiwara, T., Tsukamoto, Y. and Ishihara, K. (2004) Response of Pile Groups against Seismically Induced Lateral Flow in Centrifuge Model Tests. Soils and Foundations, 44, 39-55. https://doi.org/10.3208/sandf.44.3 39

[14] Ashford, S.A., Juirnarongrit, T., Sugano, T. and Hamada, M. (2006) Soil-Pile Response to Blast-Induced Lateral Spreading. I: Field Test. Journal of Geotechnical and Geoenvironmental Engineering, 132, 152-162. https://doi.org/10.1061/(ASCE)1090-0241(2006)132:2(152)

[15] Abdoun, T. (1997) Modeling of Seismically Induced Lateral Spreading of Multi-Layered Soil and Its Effect on Pile Foundations. PhD Thesis, Rensselaer Polytechnic Institute, Troy, New York.

[16] He, L., Elgamal, A., Abdoun, T., Abe, A., Dobry, R. and Hamada, M. (2009) Liquefaction-Induced Lateral Load on Pile in a Medium Dr Sand Layer. Journal of Earthquake Engineering, 13, 916-938. https://doi.org/10.1080/13632460903038607

[17] Abdoun, T. and Dobry, R. (2002) Evaluation of Pile Foundation Response to Lateral Spreading. Soil Dynamics and Earthquake Engineering, 22, 1051-1058. https://doi.org/10.1016/S0267-7261(02)00130-6

[18] Dungca, J.R., Kuwano, J., Takahashi, A., Saruwatari, T., Izawa, J., Suzuki, H. and Tokimatsu, K. (2006) Shaking Table Tests on the Lateral Response of a Pile Buried in Liquefied Sand. Soil Dynamics and Earthquake Engineering, 26, 287-295. https://doi.org/10.1016/j.soildyn.2005.02.021

[19] Hamada, M. (2000) Performances of Foundations against Liquefaction-Induced Permanent Ground Displacements. Proceedings of the 12th World Conference on Earthquake Engineering, Auckland, Paper No. 1754.

[20] Boulanger, R.W., Curras, C.J., Kutter, B.L., Wilson, D.W. and Abghari, A. (1999) Seismic Soil-Pile-Structure Interaction Experiments and Analyses. Journal of Geotechnical and Geoenvironmental Engineering, 125, 750-759. https://doi.org/10.1061/(ASCE)1090-0241(1999)125:9(750)

[21] Rollins, K.M., Gerber, T.M., Lane, J.D. and Ashford, S.A. (2005) Lateral Resistance of a Full-Scale Pile Group in Liquefied Sand. Journal of Geotechnical and Geoenvironmental Engineering, 131, 115-125. https://doi.org/10.1061/(ASCE)1090-0241(2005)131:1(115)

[22] Brandenberg, S.J., Boulanger, R.W., Kutter, B.L. and Chang, D. (2005) Behavior of Pile Foundations in Laterally Spreading Ground during Centrifuge Tests. Journal of Geotechnical and Geoenvironmental Engineering, 131, 1378-1391. https://doi.org/10.1061/(ASCE)1090-0241(2005)131:11(1378) 
[23] Cubrinovski, M., Kokusho, T. and Ishihara, K. (2006) Interpretation from Large-Scale Shake Table Tests on Piles Undergoing Lateral Spreading in Liquefied Soils. Soil Dynamics Earthquake Engineering, 26, 275-286. https://doi.org/10.1016/j.soildyn.2005.02.018

[24] Yang, Z.H., Elgamal, A. (2002) Influence of Permeability on Liquefaction-Induced Shear Deformation. Journal of Engineering Mechanics, 128, 720-729. https://doi.org/10.1061/(ASCE)0733-9399(2002)128:7(720)

[25] Yoshimine, M., Nishizaki, H., Amano, K. and Hosono, Y. (2006) Flow Deformation of Liquefied Sand under Constant Shear Load and Its Application to Analysis of Flow Slide of Infinite Slope. Soil Dynamics Earthquake Engineering, 26, 253-264. https://doi.org/10.1016/j.soildyn.2005.02.016

[26] Sasaki, Y., Towhata, I., Tokida, K., Yamada, K. and Saya, S. (1992) Mechanism of Permanent Displacement of Ground Caused by Seismic Liquefaction. Soils and Foundations, 32, 79-96. https://doi.org/10.3208/sandf1972.32.3 79

[27] Towhata, I., Vargas-Monge, W., Orense, R.P. and Yao, M. (1999) Shaking Table Tests on Subgrade Reaction of Pipe Embedded in Sandy Liquefied Subsoil. Soil Dynamics and Earthquake Engineering, 18, 347-361.

https://doi.org/10.1016/S0267-7261(99)00008-1

[28] Hwang, J.I., Kim, C.Y., Chung, C.K. and Kim, M.M. (2006) Viscous Fluid Characteristics of Liquefied Soils and Behavior of Piles Subjected to Flow of Liquefied Soils. Soil Dynamics Earthquake Engineering, 26, 313-323. https://doi.org/10.1016/j.soildyn.2005.02.020

[29] Hadush, S., Yashima, A., Uzuoka, R., Moriguchi, S. and Sawada, K. (2001) Liquefaction Induced Lateral Spread Analysis Using the CIP Method. Computers and Geotechnics, 28, 549-574. https://doi.org/10.1016/S0266-352X(01)00016-7

[30] Issa, R.I. (1986) Solution of the Implicitly Discretized Fluid Flow Equation by Operator Splitting. Journal of Computational Physics, 62, 40-65. https://doi.org/10.1016/0021-9991(86)90099-9

[31] Oliveira, P.J. and Issa, R.I. (2001) An Improved PISO Algorithm for the Computation of Buoyancy-Driven Flows. Numerical Heat Transfer, Part B: Fundamentals, 40, 473-493. https://doi.org/10.1080/104077901753306601

[32] Barton, I.E. (1998) Comparison of SIMPLE- and PISO-Type Algorithms for Transient Flows. International Journal for Numerical Methods in Fluids, 26, 459-483. https://doi.org/10.1002/(SICI)1097-0363(19980228)26:4<459::AID-FLD645>3.0.CO; $\underline{2-\mathrm{U}}$

[33] Su, L., Tang, L., Ling, X., Liu, C. and Zhang, X. (2016) Pile Response to Liquefaction-Induced Lateral Spreading: A Shake-Table Investigation. Soil Dynamics and Earthquake Engineering, 82, 196-204. https://doi.org/10.1016/j.soildyn.2015.12.013

[34] Dobry, R., Abdoun, T., O’Rourke, T.D. and Goh, S.H. (2003) Single Piles in Lateral Spreads: Field Bending Moment Evaluation. Journal of Geotechnical and Geoenvironmental Engineering, 129, 879-889. https://doi.org/10.1061/(ASCE)1090-0241(2003)129:10(879)

[35] Japan Road Association (2002) Specifications for Highway Bridges: Part V Seismic Design. Tokyo.

[36] Wilson, D.W., Boulanger, R.W. and Kutter, B.L. (2000) Observed Seismic Lateral Resistance of Liquefying Sand. Journal of Geotechnical and Geoenvironmental Engineering, 126, 898-906. https://doi.org/10.1061/(ASCE)1090-0241(2000)126:10(898) 
[37] American Petroleum Institute (2000) Recommended Practice for Planning, Designing and Constructing Fixed Offshore Platforms-Working Stress Design.

[38] Guo, D.W., Lu, W.W. and Tian, Z.N. (2014) Simulation of Pile-Soil Interaction by p-y Curves Method. China Water Transport, 14, 109-112. (In Chinese)

[39] Li, Y.R., Yuan, X.M. and Yan, L. (2009) Modified Calculation Method of p-y Curves for Liquefied Soil-Pile Interaction. China Civil Engineering Journal, 34, 595-599. (In Chinese)

[40] Kazuya, Y., Toyatoshi, Y. and Kazutoshi, H. (1982) Cyclic Strength and Deformation of Normally Consolidated Clay. Japanese Society of Soil Mechanics and Foundation Engineering, 22, 77-91. https://doi.org/10.3208/sandf1972.22.3 77

[41] Jiang, J. (2002) Study on the Strain Rate of Clay under Cyclic Loading. China Civil Engineering Journal, 24, 528-531. (In Chinese)

[42] Ramos, R., Abdoun, T. and Dobry, R. (1999) Centrifuge Modeling of Effect of Superstructure Stiffness on Pile Bending Moments Due to Lateral Spreading. Proceedings of the 7 th US-Japan Workshop on Earthquake Resistant Design of Lifeline Facilities and Countermeasures against Soil Liquefaction, Seattle, 15 August 1999, 599-608. 